\title{
Investigating the Opinions of Teachers on the Processes of Vocational Counselling, Training and Employment of Special Needs Students
}

\author{
Ahmet Bilal Özbek ${ }^{1}$, Alev Girli ${ }^{2}$, Halil Öztürk ${ }^{2}$ \\ ${ }^{1}$ Faculty of Educational Sciences, Department of Special Education, Ankara University, Ankara, Turkey \\ ${ }^{2}$ Buca Faculty of Education, Department of Special Education, Dokuz Eylül University, İzmir, Turkey \\ Correspondence: Halil Öztürk, Buca Faculty of Education, Department of Special Education, Dokuz Eylül University, \\ İzmir, Turkey.
}

Received: October 24, 2017

Accepted: November 7, $2017 \quad$ Online Published: November 13, 2017

doi:10.11114/jets.v5i12.2734

URL: https://doi.org/10.11114/jets.v5i12.2734

\begin{abstract}
The statistics of the Ministry of National Education (MEB) show that the number of students who are pursuing their education in general education environments in scope of inclusion programs is increasing every year. It is observed that the number of special needs students who continue their secondary education after primary education is increasing with the regulation that makes it mandatory to have 12 years of education. While directing special needs (SN) students towards secondary education, families and experts prefer vocational high schools where these students can learn functional skills. This is why the opinions of teachers who work at vocational high schools are important. The purpose of this study is to investigate the opinions of technical teachers working at vocational high schools, school counsellors, culture course teachers and special education teachers providing support education to students on the processes of vocational counselling, training and employment of special needs students. Towards this purpose, semi-structured interviews were held with a total of 59 teachers using a form prepared by the researchers. The findings indicated that the opinions of technical teachers at vocational high schools on inclusion and continuation of SN students in vocational high schools were more negative in comparison to those of culture course teachers and school counsellors, and there were significant shortcomings in the professional training of SN students. It was also seen that special needs teachers were not sufficiently informed about the job prospects and employment of SN students, and they used limited opportunities for their students.
\end{abstract}

Keywords: special needs students, vocational education, vocational counselling, special education

\section{Introduction}

It is seen that there is an increasing number of students who are utilizing the practice of inclusion, which is defined as defending the idea of equal access to educational means by all students without regards to limitations based on the concept of social justice (Sharma, Forlin, Loreman \& Earle, 2006) and participation by special needs students in the same education environment with their peers in practice and receive support services (Odom, 2000). Especially after the regulation known as $4+4+4$ brought in 2012 which made it compulsory to receive 12 years of education, a vast increase was experienced in the rate of special needs students who continued their secondary education after primary education. The 2016-2017 statistics of the Ministry of National Education (MEB) reported that 33,658 special needs students are attending high schools in scope of inclusion implementations. On the level of middle schools, there are 105,333 special needs students.

Despite the increased number of students, it is seen that teachers are not utilizing supportive special education services sufficiently. It is reported that this may affect inclusion practices negatively, as well as negatively influencing the attitudes of especially teachers who have special needs students in their classroom (Kargin, 2004). Several studies have shown that inclusive education provides academic, social and behavioral benefits to students with limitations, and other students in the classroom and teachers also utilize these benefits (Logan \& Malone, 1998; McDonnell, Thorson \& McQuivey, 2000). Studies on the attitudes and beliefs of teachers, who are crucial in achieving success in inclusion practices (Norwich, 1994) reported that there are positive developments of teachers' attitudes towards inclusion practices in time, and teachers complain about lack of information and insufficient support services (Casale-Giannola, 2012; Press, Foote \& Rinaldo, 2010; Rose, Kaikkonen \& Koiv, 2007; Van Reusen, Shoho \& Barker, 2000; Vaughn, 
Schumm, Jallad, Slusher \& Saumell, 1996). It was seen that negative teacher attitudes were also influential on reaching success in inclusion practices in the secondary stage (Worrell, 2008).

While there are positive developments in vocational training and employment of special needs individuals in Turkey, there are not studies on a desired level or in a desired number yet. Considering the 'Report on Disability and Development in Turkey in the Last Decade' by the Ministry of Family Affairs and Social Policy, it is seen that significant steps have been taken for employment of special needs individuals. A regulation was made in the civil servants' law for special needs individuals, and the 'Examination for Selection of Disabled Civil Servants (OMSS)' was initiated in 2012. It is stated that there has been a significant increase in the number of special needs individuals who work in public offices with this regulation. Additionally, it was aimed to increase employment of special needs individuals with state support for the private sector and the practice of 'obligation to employ disabled workers'. It is seen that there are positive developments in terms of employment of special needs individuals. However, in order for special needs students to be able to utilize these opportunities, they need sufficient and effective vocational education. In order to achieve complete transition of special needs students into professional life, post-education support is needed from an interdisciplinary team (Levinson \& Palmer, 2005).

Review of the studies in Turkey on the attitudes and opinions of teachers towards inclusion showed that, they were on pre-school teachers (Özdemir \& Ahmetoğlu, 2012; Seçer, 2010; Temel, 2000), primary education form teachers and prospective form teachers (Çankaya \& Korkmaz, 2012; Kargın, Güldenoğlu \& Şahin, 2010), and these studies reported that teachers had negative views on inclusion. It was seen that studies on inclusion practices in vocational high schools are limited in number. In the study by Batu, Kurcaali-İftar and Uzuner (2000), the teachers stated that they had insufficient knowledge about inclusion, and benefits provided to students with limitation led to problems with other students. In a study which investigated the attitudes of teachers employed at vocational high schools, it was found that the teachers had negative views about attendance of special needs students to vocational high schools (Özbek, Girli \& Erdoğan, 2013). Studies on the employment and hiring processes of special needs individuals emphasize the need for qualified vocational training which prepares the individual for professional life (Baran \& Cavkaytar, 2007; Çavuş \& Tekin, 2015; Genç \& Çat, 2013; Gökbay, Ergen \& Özdemir, 2011; Güneş \& Akçamete, 2014). In this context, there is a need for new studies towards increasing the quality of the education received by special needs students at vocational high schools within 12 years of compulsory education.

This study interviewed special needs teachers, school counsellors, culture course teachers and technical teachers working at vocational high schools and aimed to provide a comprehensive description of their experiences and the problems they encounter. It is believed that, with this aspect, the study will make a contribution to the literature in terms of providing data needed regarding the process of inclusion applied in vocational high schools in Turkey. The purpose of this study is to investigate the opinions teachers on the processes of vocational counselling, training and employment of special needs students, and determine the existing problems.

\section{Method}

\subsection{Study Model}

This study employed a qualitative research method, and this method was chosen because it allows collection of in-depth and detailed data from the selected sample. Qualitative research techniques have a comprehensive approach and the allow revelation of perceptions with inductive analysis (Yıldırım \& Şimşek, 2008).

\subsection{Sample}

The teachers in the sample were selected in compliance with the criteria determined based on the method of criterion sampling. In criterion sampling, the sample is formed with individuals, events, objects or cases that have the characteristics required by the research question (Ekiz, 2003). The criteria for selection were that the teachers have worked with SN students in their classroom within inclusion practices and that they were employed at vocational high schools. The sample consisted of 59 teachers who were employed at vocational high schools and special education schools. 13 of the teachers were culture course teachers, 8 were school counsellors, 19 were technical teachers and 19 were special education teachers. 35 of the teachers in the sample were female, 24 teachers were male, and their mean age was 41.8 teachers had a professional experience of 2-5 years, 8 had an experience of 6-10 years, 12 had an experience of 11-20 year, and 31 teachers had an experience of 21 years or longer.

\subsection{Data Collection}

The data were collected using a semi-structured interview form prepared by the researchers. The interview form contained 6 common questions for all teachers, and other questions specially prepared base on the teachers' subjects, 2 for the special education teachers, 4 for the school counsellors, 4 for the culture course teachers and 4 for the technical teachers. Audio recording was made during the interview by the consent of the teachers. The interviews were held 
individually, and they lasted for about 10-15 minutes. The question asked to the teachers are given below:

\subsubsection{Common Questions}

1. What are your thoughts about special needs students receiving education with their peers in scope of inclusion practices?

2. What are your thoughts about special needs students receiving education at high schools/vocational high schools?

3. Which fields of vocational education, in your opinion, can special needs students be directed towards? Why do you think these professions are suitable for special needs students?

4. What are the problems you encounter through the education process of special needs students?

5. What kind of arrangements do you include in your classes for special needs students?

6. Are there workplaces in Turkey that are suitable for special needs students with these professions? If there are, what do you think are these?

\subsubsection{Questions for Technical Teachers (Vocational High School Teachers)}

1. What can be done for special needs students to learn the skills that will allow them to work independently in this field? Do you think special needs students can be made independent in the necessary professional skills?

2. Are you making special adaptations/arrangements for special needs students in professional internship practices? If you are, what are these?

3. What do you think about active participation and employment of the students who graduated from the field of profession you are teaching in professional life?

4. Do you cooperate with organizations such as ISKUR (Turkish Employment Organization) for employment of special needs students? How? Can you elaborate?

\subsubsection{Questions for School Counsellors}

1. What can be done to increase the quality of the education received by special needs students at vocational high schools?

2. What do you think about adaptation of special needs students to the school and supporting their processes of transitioning from primary education to secondary education? What can be done by school counselling services in this process?

3. What do you think about supporting the processes of special needs students to transition from school into professional life? What are you doing in this process as a school counsellor? What do you think school counselling services can do?

4. Regarding provision of the support the student needs while working at a unit after graduation and control of working conditions,

a. What can school counsellors do? What do you think about this issue?

b. What are you doing for this issue?

\subsubsection{Questions for Culture Course Teachers (Subject: Physics, Chemistry, Literature, Mathematics)}

1. What do you think about the effects of the course you are teaching on the vocational skills of special needs students and their hiring process?

2. Do you think the course you are teaching is suitable for special needs students?

3. What do you think about supporting the processes of special needs students to transition from school into professional life?

4. Do you think special needs students can work independently at a job after the vocational education they receive? Do you think there are sufficient work/arrangements being made in your school?

\subsubsection{Questions for Special Education Teachers}

1. Are you making special adaptations/arrangements for your special needs students in professional internship practices? If you are, what are these?

2. Regarding provision of the support the student needs while working at a unit after graduation and controlling working conditions, what do you think special education teachers should do? To what extent and how are you able to do this for the students you previously got hired? 


\subsection{Data Analysis}

The data were analyzed using the method of descriptive analysis. In descriptive analysis, the data are summarized and interpreted based on pre-determined themes. The purpose is to present the findings to the reader in an organized and interpreted way (Yıldırım \& Şimşek, 2008). Audio recordings were listened to and transferred into text, the information was organized with the purpose of reduction, and coded. After coding, themes were formed based on common responses. The responses given to the common questions were analyzed by evaluation of the responses by all the teachers together. It was aimed to increase the validity of the study by including quotes from the opinions of the teachers in the sample in the findings section. The data were analyzed by the second and third researchers, and a randomly-selected $40 \%$ of the data were analyzed by the first researcher as well. Evaluation reliability was assessed based on agreement and disagreements. Based on the reliability formula by Miles and Huberman (1994), the reliability rate of the study was found to be $93 \%$.

\section{Results}

The findings are presented as the responses by all teachers to 6 common questions and the responses by subject/field teachers to the questions about their subject/field. In this section, K: culture course teacher, T: technical teacher, R: school counsellor, and Ö: special education teacher.

\subsection{Results on the Responses Given to the Common Question}

The responses to the 6 questions directed to all the teachers in the sample were examined and 6 sub-themes were formed. These are; 1. Opinions on inclusion practices, 2. Inclusion practices at vocational high schools, 3. Professions suitable for special needs students, 4. Problems experienced in the education process, 5. Arrangements included in classes, 6. Existing opportunities of work.

\subsubsection{Opinions on Inclusion Practices}

While $86.44 \%$ ( $n=51$ ) of the teachers stated positive views on special needs students' continuation of their education with their peers in scope of inclusion practices, $13.56 \%(n=9)$ stated that they did not agree with inclusion practices. All teachers who stated negative views about inclusion practices were the teachers of technical courses employed at vocational high schools. As examples of positive responses by the teachers, K11: 'I think it is important and useful for settling them into the society, T10: 'I find it highly positive, it is a practice that will have very beautiful and good results', R6 'I find it positive, they are very different while starting school and graduating, they improve a lot, they are accepted. It is a good thing', Ö19: 'I think it will be suitable when students taken in for inclusion are placed correctly'. On the other hand, T16: 'I do not find it very appropriate. The state should open separate schools for these children, special teachers should take care of them. We do not have sufficient knowledge. They are lost among normal children.'

\subsubsection{Inclusion Practices at Vocational High Schools}

Based on the responses of the teachers in the sample on continuation of special needs students in secondary education, $20.33 \%(\mathrm{n}=12)$ (10 technical teachers, 1 school counsellor, 1 special education teacher) had negative views, while $79.67 \%$ $(\mathrm{n}=48)$ had positive views. As examples of both positive and negative views, K4: 'Vocational high schools are especially the most suitable ones for them to participate in life', T10: 'I find it necessary and essential, we will see its use in the future', R8: 'As vocational high schools are applied, they are more suitable. They would find it harder at other high schools, the coursework is very heavy', Ö11: 'I think they should continue. I think there are jobs that can be achieved for every student, T17: 'Vocational high schools... No. They are not suitable. They should definitely study at special vocational high schools. Our schools are very difficult for them, R2: 'Vocational high schools are not easy. They find it really difficult. Classes like computer education overwhelm them, Ö14: 'Vocational high schools do not provide the necessary attention. Special vocational education is more suitable'.

\subsubsection{Professions Suitable for Special Needs Students}

$83.06 \%(\mathrm{n}=50)$ of the teachers stated that special needs students can work at routine jobs based on hand skills, 5.08\% $(n=3)$ said it is needed to make placements based on a skills test and $11.86 \%(n=7)$ direction should be made based on their interests and wishes. Examples of the responses by the teachers; K7: 'Handicrafts like the department of woodworking, applied jobs such as home economics, gardening, agriculture are good. They are able to do these', K10:'Based on their skills, handicrafts, foods, agriculture are fields with fewer risks, they are suitable', T3: 'They should be directed to fields they can be successful in practice, those they are interested in.', T11: 'Based on their disability, it may be clerkship, desk jobs, handicrafts, needlework, or being a barber. Of course, they should have a more qualified supervisor', T19: 'They should take skill tests. If they are successful in these tests, they can continue vocational education', R4: 'They should be directed to vocational courses. They can get jobs based on their personality and mental traits', Ö16: 'They can work in fields of work where they can always do the same thing without much variety. I am thinking of construction, painting, textile fields'. 


\subsubsection{Problems Experienced in the Education Process}

The responses by the teachers included three sub-themes as insufficient physical environment $20.28 \%(\mathrm{n}=12)$, problems arising from families $45.63 \%(\mathrm{n}=27)$ and problems arising from special needs students $67.6 \%(\mathrm{n}=40)$. As examples of problems arising from special needs students, $\mathrm{K} 3$ : 'There are communication problems, and as they are introverted, we are experiencing problems of participation in the class.', T3: 'They are absent for many occasions due to disability or illness, this is actually the biggest problems.', T16: 'Attention deficiencies and forgetting easy are among the biggest problems. We are making no progress'. K13: 'Physical conditions and lack of studies are problems.', which indicates insufficiency of physical conditions, while examples of problems arising from families include; R8: 'We have problems of acceptance by the family and the society, of course, but additionally, there is no suitable curriculum. It is very hard to follow the curriculum. The curriculum is hard for the children.', Ö3: 'Lack of education and information of the family... Families' expectations from us and the children are too high'.

\subsubsection{Arrangement Included in Classes}

When the teachers were asked about the arrangements they made for special needs students, $67.6 \%(\mathrm{n}=40)$ said they made simplifications in subjects and tasks, $40.56 \%(\mathrm{n}=24)$ stated that they utilized the individualized education programs (IEPs) of the students, 5.08\% ( $\mathrm{n}=3)$ said they did not make any arrangements, $54.24 \%(\mathrm{n}=32)$ said they arrange environments and tools, and $3.38 \%(\mathrm{n}=2)$ stated that they showed attention and love. As examples of the responses by the teachers, K3: 'I simplify things, try to motivate them, and accept the result even when it is incomplete.', K12: 'I show attention and love. I give them confidence.', T2: 'I get them to use simple machines and equipment. I get them to repeat frequently.', T19: 'We are giving them different tasks to keep them busy during the classes. The curriculum is hard for them. We cannot handle the same subject. We are giving them simple tasks, like simpler homework.', Ö13: 'We are preparing IEPs, organizing physical conditions, making dangerous areas more suitable'. This question was not answered by the school counsellors as they did not take an active part in teaching.

\subsubsection{Existing Opportunities of Work}

For the question about opportunities of work that are suitable for special needs students, $3.38 \%(n=2)$ of the teachers said there is no opportunity to work, $16.9 \%(\mathrm{n}=10)$ stated that they did not have knowledge, $60.84 \%(\mathrm{n}=36)$ said there are opportunities but not enough and $18.59 \%(\mathrm{n}=11)$ said there are opportunities. 7 of the teachers who stated that they had no knowledge were special education teachers. As examples of the responses by the teachers, K7: 'There are some areas of work. The state places them at suitable jobs. The state has come a long way in the last ten years.', K9: 'I do not have complete knowledge, but I think there are not any, because none of my students is working.', T9: 'There are some, but not enough. They work at café, cargo transportation, cleaning jobs.', T16: 'There are children who are very suitable for what we call bookbindery, like printing, paper jobs. They can do repetitive and simple jobs very comfortably.', R4: 'The state provides great support and implementations. For instance, there is a requirement to employ a disabled person in all workplaces.', Ö4: 'I find these insufficient. In general, they are simple jobs. Variety is needed.', Ö13: 'I know that establishments with 50 or more employees have to employ them. There probably are some opportunities'.

\subsection{Responses by the Culture Course Teachers}

The teachers of subjects such as Physics, Chemistry, Literature and Mathematics at vocational high schools were asked four questions, and four main themes were formed. Sub-themes were formed for some questions.

\subsubsection{Effects of the Course on Special Need Students' Job Skills and Employment}

$15.38 \%(\mathrm{n}=2)$ of the teachers stated that they had no idea about this issue, $76.9 \%(\mathrm{n}=10)$ stated that their classes are effective and important, and $7.69 \%(\mathrm{n}=1)$ said their class did not have an influence. As examples of the responses by the teachers: K8: 'Well, it is based on their situation. That is, it may be helpful for the disabled civil servant selection exam. I am doing my best.', K10: 'My subject is difficult and unsuitable for children with disabilities.', K12: 'The visual arts course improves their skills and responsibility'.

\subsubsection{Suitability of the Course for Special Needs Students}

$100 \%(n=13)$ of the teachers stated that their subject is not suitable for special needs students; however, $92.31 \%(n=12)$ said they tried to make the curriculum more suitable by simplifying it. The responses by the teachers were similar in nature; K4: 'The high school curriculum is very heavy. It becomes suitable only by simplification.', K9: 'The course is suitable, but some subjects and curricula are not very suitable'.

\subsubsection{Special Needs Students' Process of Transition to Professional Life}

$100 \%(\mathrm{n}=13)$ of the teachers stated that special needs students should be supported in their processes of transition to professional life. As examples for the responses, K3: 'Teachers and schools are limited. Employers and the state should take responsibility. We are preparing our students. They should create opportunities of work and employment.', K7: 'It 
should definitely be kept tabs on and supported. Teachers and the administration have responsibility for directing them to work.', K11: 'It should definitely be supported. They experience adaptation problems. Support should be provided for some time in the transition process. They may give up when not supported'. $100 \%(n=13)$ of the teachers stated that they were not making any arrangements for supporting SN students' transition to professional life.

\subsubsection{Independent Working by Special Needs Students}

The views of the culture course teachers on this issue were collected under three groups. Those who though special needs students can work independently were $15.38(n=2)$ of the teachers, while $61.52 \%(n=8)$ stated they need to have a capable person supervising them and $23.07 \%(\mathrm{n}=3$ ) said they cannot work independently. As examples of this issue, K6: 'They can work independently. Children who can already function independently at school can also make it in professional life. There is no sufficient transition support yet.', K8: 'I think it is not possible in the existing society and educational order for them to become independent. A more responsible society and a support system are needed.', K11: 'They can work independently, but do not have sufficient arrangements in our school. It is needed to provide sufficient amount of practice'.

\subsection{Responses by the Technical Teachers}

The responses by the teachers to four questions in this section were collected under to main themes as 1 . Arrangements about the internship proves and 2. Employment problems and recommendations.

\subsubsection{Internship Arrangements}

$36.82 \%(n=7)$ of the technical teachers stated that they did not make any arrangement for SN students, while $63.12 \%$ $(n=12)$ stated that they did. Those who made arrangements used the following statements; T11: "As there are insufficient environments and opportunities, internships are also insufficient. We talk to the place of internship, convince them and make explanations. We are providing simpler goals and tasks', T19: 'Businesses are made aware. We are visiting the businesses every week', T1: 'We cannot. This is because there is the business' side. Businesses rarely accept such students. They do not want to deal with them'.

\subsubsection{Employment Problems and Recommendations}

The field of employment was divided into three sub-themes. These are;

Independent working situations of special needs students: $15.78 \%(n=3)$ teachers stated that SN students cannot work independently, while $84.22 \%(\mathrm{n}=16)$ said they can be independent based on the state of their disability and quality education. As examples to the responses, T3: 'Lengths of education and curricula should be reviewed. It is possible with better education', T17: 'More one on one work with students is needed. This way, they can become independent. The classroom's population should be lower and special attention should be paid'.

Recommendations for employment of students: Technical teachers recommended that quality of education should be increased, and some legal regulations should be made for increasing employment of special needs students. $26.3(\mathrm{n}=5)$ stated that there is a need for higher quality education, while $73.7 \%(\mathrm{n}=14)$ said obligations should be brought by legislation. T2: 'Teaching the job well increases the rate of employment. They should become qualified personnel.', T17: 'Employment rate will increase with a teacher who is the same person from the beginning to the end and intense education'.

Collaborations and projects the teachers conduct for students' employment: $73.7 \%(n=14)$ of the teachers stated that they did not have any project or collaboration on this issue, while $26.3 \%(n=5)$ said they made institutional collaborations. T4: 'Yes, we have collaborations. We are opening courses that have guaranteed employment with İSKUR.', T17: 'Yes, we have vocational course with İŞKUR.', T18: 'We are taking initiatives for employment. We have spoken to the municipality, İşKUR and private organizations. We have initiatives, and it will be a good opportunity for the children'.

\subsection{Responses by the School Counsellors}

The school counsellors were asked four questions and with the responses, sub-themes were formed under four main themes.

\subsubsection{Quality of the Vocational Education of SN Students}

All $(100 \%, \mathrm{n}=8)$ school counsellors stated that the quality of the education given to SN students at vocational high schools was low. They stated the reasons for this as lack of knowledge by teachers and administrators $(50 \%, \mathrm{n}=4)$, lack of studios and suitable environments $(37.5 \%, \mathrm{n}=3)$ and that the student was not suitably directed $(12.5, \mathrm{n}=1)$. R6: 'More training for teachers. There is too much lack of knowledge. There are those who have not taken special education classes.', R2: 'Students should be directed towards occupations that are suitable for their skills. These should be suitable 
for their disabilities. Heavy curriculum overwhelms them. There should be more applied field'.

\subsubsection{SN Students' Process of Transition from Primary Education to Secondary Education}

Only $1(12.5 \%)$ counsellor stated that they did work of social acceptance regarding the SN students' process of adaptation to the school and transition, while $87.5 \%(n=7)$ stated that they were not able to provide sufficient support. As examples, R2: 'Students should be introduced better and social acceptance should be established. Rules in high school are stricter. The children cannot get used to them right away. Of course, in-school arrangements are also important.', R4: 'When they come to high school, they show very low-level performance. It is needed to provide performance support suitable for high school.', R6: 'Introductions should be made for them to join departments that are suitable for their characteristics. Families should be informed on this issue. There is a need for a transition system. For example, the child is registered to the department of accounting, be he cannot do it'.

\subsubsection{SN Students' Process of Transitioning into Professional Life}

When the teachers were asked what is being done by counselling services while the students are transitioning into professional life, $100 \%(\mathrm{n}=8)$ stated that they did not make any arrangements. R6: 'We are not doing anything for this issue. The children get hired by their own means or through e-kpss (civil servant employment examination for the disabled).', R5: 'It is a really hard task. Children are usually at home. Those except ones with mental disability are easier, but still, they are not preferred. We have not had such an arrangement'.

\subsubsection{Supporting SN Students after Graduation}

Regarding the issue of supporting SN students after graduation, $100 \%(\mathrm{n}=8)$ stated that they had not made any arrangements. $62.5 \%(n=5)$ said there is a need for legal regulations and collaboration. As examples to the responses, R2: 'A school counsellor's field of work is limited. We have small influence on professional life. There is a need for arrangements through regulation.', R7: 'We do not have a procedure for alumni. It is very difficult to follow them. If they come to us, we inform them. The rest is for the family to deal with'.

\subsection{Responses by the Special Education Teachers}

During the interviews carried out with special education teachers who work at vocational special education centers and vocational courses, their views were determined by asking them two questions. The responses were collected under two main themes.

\subsubsection{Internship Arrangements for Special Needs Students}

While $31.56 \%(\mathrm{n}=6)$ of the teachers reported that they did not include any internship arrangements for their students $68.44 \%(\mathrm{n}=13)$ stated that they made internship arrangements. In general, their responses were as the following; Ö11: 'It is highly important to inform the business. We are doing this as much as possible. We are stating the issues they should pay attention to and warning them.', Ö18: 'We are trying to make arrangements based on the type of disability'.

\subsubsection{Special Needs Students Transition into Professional Life after Graduation}

$100 \%(\mathrm{n}=19)$ of the teachers stated that there is no follow-up and transition service after graduation. Among these teachers, $26.3 \%(n=4)$ stated that there is a need for a follow-up and transition system and such a system should be established. The vast majority of the teachers $(73.7 \%, \mathrm{n}=15)$ stated that this is not the school's job after graduation. As an example to the views of the special education teachers, Ö9: 'There should be a follow-up of at least two years after employment. It should be checked in certain intervals. We are receiving information from the workplaces of the students we previously got positioned'. As an example to the views of those who thought this was not their job, Ö14: 'We are not following them after graduation. We do not have such a duty in the system'.

\section{Discussion and Conclusion}

This study aimed to investigate the opinions of teachers at vocational high schools on continuation of special needs students in vocational education with their pears in scope of inclusion practices, processes of directing them towards jobs and professions, and their employment. As a result of the analysis of the views, it was found that the teachers generally had positive views towards inclusion, but they had significant lack of knowledge, and they experienced significant problems regarding both the curriculum and the means at the school. These results are similar to those in the literature (Batu, Kırcaali-İftar \& Uzuner, 2000; Özbek, Girli \& Erdoğan, 2013). In particular, it was seen that the teachers had little professional experience in terms of teaching skills to special needs individuals, and they had limited knowledge about the existing opportunities and legal rights for special needs individuals' employment. This case is also seen in similar studies (Casale-Giannola, 2012; Rose, Kaikkonen \& Köiv, 2007).

It was observed that, among the teachers from different disciplines in the sample, the least ambitious group about vocational education of special need individuals was the teachers of technical courses. It is a serious problem for 
succeeding in inclusion practices that the teachers of technical courses, which have an important role in reaching the goals of vocational education, had negative views. As the reasons for these negative views, the technical teachers reported that "special needs students are not directed towards suitable vocational departments, no professional choices that are suitable for their disabilities are made, and the means of studios and populations of classrooms prevent them from carrying out applied work." Weddel (2005) reported that physical conditions such as class sizes are important. Therefore, it may be expected that the views of technical teachers may be turned positive when the arrangements that are the subjects of complaint are made. Several studies demonstrated that the attitudes of teachers are positive in inclusion environments where the correct implementations are made, and necessary support services are provided (Batu \& Topsakal, 2003; Batu et al., 2006)

Another interesting result of the study was that, the responses by most of the teachers to the question about professions or jobs that special needs students can do included 'routine jobs that include hand skills'. When they were asked about fields of work for special needs individuals, it was seen that they stated applied fields that require simple skills, which they called 'low-risk jobs'. The teachers who also stated that the interests and skills of the students are also important were a minority. The responses received from the teachers suggest that there is a latent expectation of low success from special needs students.

It was seen that the participants agreed on the idea that the current system is insufficient in terms of special needs students' transition to secondary education, and supporting and following-up on them in professional life after vocational education. This situation was reported in other studies as special needs students are not prepared for professional life and their work in protected environment prevents them from becoming independent (Baran \& Cavkaytar, 2015; Güneş \& Akçamete, 2014). Considering the responses by the school counsellors and technical teachers regarding transition processes, it was observed that the support and direction needed by special needs students is not provided. All teachers in the sample stated that there is a need for a system regarding direction of students towards suitable professional fields, supporting them against problems they may experience in the transition problems, and keeping tabs on them in the processes of vocational education and transition into professional life. The responses by the teachers are similar to the description of characteristics that experts who will support transition processes should have as reported by Defur and Taymans (1995). When considered in the context of 12 years of compulsory education, as the number of special needs students who will continue secondary education will increase each year, studies on transition processes are a necessity.

This study is limited to the views of 59 teachers in the sample, and this limitation should be considered while interpreting the results. It is important for increasing the rate of employment and quality of vocational education for special needs individuals to reveal the existing situation and needs in more detail by studies which will have larger samples and work with teachers working at schools in different locations.

\section{References}

Baran, N., \& Cavkaytar, A. (2007). Opinions and suggestions of employers on employment of individuals with mental retardation. Elementary Education Online, 6(2), 213-225.

Batu, E. S., Kırcaali-İftar, G., \& Uzuner, Y. (2006). The opinions and suggestions of teachers who are working in a vocational school about inclusion. Ankara University Faculty of Educational Sciences Journal of Special Education, 5(2), 33-50.

Batu, S., \& Topsakal, M. (2003). Special education counseling process and consulting example. Ankara University Faculty of Educational Sciences Journal of Special Education, 4(1), 19-29.

Cankaya, Ö., \& Korkmaz, İ. (2012). The evaluation of elementary teachers' perceptions about implementation of inclusive education. Ahi Evran University Journal of Kırşehir Education Faculty, 13(1), 1-16.

Casale-Giannola, D. (2012). Comparing inclusion in the secondary vocational and academic classrooms: strengths, needs, and recommendations. American Secondary Education, 40(2), 26-42.

Çavuş, Ö. H., \& Tekin, A. (2015). Sheltered workplace as a method of employment for the disabled people in Turkey. Dokuz Eylül University Journal of Faculty of Economics and Administrative Sciences, 30(1), 145-165.

Defur, S. H., \& Taymans, J. M. (1995). Competencies needed for transition specialists in vocational rehabilitation vocational education, and special Education. Exceptional Children, 62(1), 38-51.

https://doi.org/10.1177/001440299506200104

Ekiz, D. (2003). Introduction to research methods and methods in education: qualitative, quantitative and critical theory methodologies. Ankara: An1 Publishing.

Genç, Y., \& Çat, G. (2013). Employment of disabled people and social inclusion relationship. Journal of Academic 
Inquiries, 8(1), 363-393.

Gökbay, İ. Z., Ergen, A., \& Özdemir, N. (2011). A case study to the employment of disabled people: "education without obstacles". Journal of Öneri, 9(36), 01-08.

Güneş, N., \& Akçamete, G. (2014). Occupational employment of individuals with special needs Çorum province example. Ankara University Faculty of Educational Sciences Journal of Special Education, 15(03), 001-015.

Kargin, T. (2004). Inclusion: definition, development and principles. Ankara University Faculty of Educational Sciences Journal of Special Education, 5(02).

Kargın, T., Güldenoğlu, B., \& Şahin, F. (2010). Opinions of the general education teachers on the adaptations for students with special needs in general education classrooms. Theory and Practice Educational Science, 10(4), 2431-2464.

Levinson, E. M., \& Palmer, E. J. (2005). Preparing students with disabilities for school-to-work transition and post-school life. Principal Leadership, 5(8), 11-15.

Logan, K. R., \& Malone, D. M. (1998). Instructional contexts for students with moderate, severe, and profound intellectual disabilities in general education elementary classrooms. Education and Training in Mental Retardation and Developmental Disabilities, 33, 62-75.

McDonnell, J., Thorson, N., \& McQuivey, C. (2000). Comparison of the instructional contexts of students with severe disabilities and their peers in general education classes. Journal of the Association for Persons with Severe Handicaps, 25, 54-58. https://doi.org/10.2511/rpsd.25.1.54

Miles, M. B., \& Huberman, A. M. (1994). Qualitative data analysis. Thousand Oaks, CA: Sage Publication.

Ministry of Family and Social Policy (2013). Disability and development report in Turkey in the last 10 years. It was accessed from http://eyh.aile.gov.tr on 20.08.2017.

Ministry of Family and Social Policy (2016). 2016 yearly activity report. It was accessed from http://eyh.aile.gov.tr on 20.08.2017.

Norwich, B. (1994). The relationship between attitudes to the integration of children with special educational needs and wider socio-political views: a US-English comparison. European Journal of Special Needs Education, 9, 91-106. https://doi.org/10.1080/0885625940090108

Odom, S. L. (2000). Preschool inclusion: what we know and where we go from here? Topics in Early Childhood Special Education, 20(1), 20-27. https://doi.org/10.1177/027112140002000104

Özbek, A. B., Girli, A., \& Erdoğan, G. (2013). Evaluation of Relationship Between the Views Towards Inclusion and the Levels of Empathy and Self-Efficacy of Vocational High School Teachers. Congresso Internacional Educaçao Inclusiva e Equidade.

Özdemir, H., \& Ahmetoğlu, E. (2011). Investigations on pre-school teachers 'occupational activities in the age and professional experiences. Journal Of Educational And Instructional Studies In The World, 68-74.

Press, L. K., Foote, C., \& Rinaldo, J. (2010). Inclusion classrooms and teachers: a survey of current practices. International of Special Education, 25(3), 43-56.

Rose, R., Kaikkonen, L., \& Köiv, K. (2007). Estonian vocational teachers' attitudes towards inclusive education for students with special educational needs'. International Journal of Special Education, 22(3), 97-108.

Seçer, Z. (2010). An analysis of the effects of in - service teacher training on Turkish preschool teachers' attitudes towards inclusion. International Journal of Early Years Education, 18(1), 43-53. https://doi.org/10.1080/09669761003693959

Sharma, U., Forlin, C., Loreman, T., \& Earle, C. (2006). Pre-service teachers' attitudes, concerns and sentiments about inclusive education: An international comparison of the novice pre-service teacher. International Journal of Special Education, 21(2), 80-93.

Temel, Z. F. (2000). Opinions of pre-school educators about the integration of disabilities. Hacettepe University Journal of Faculty of Education, 18, 148-155.

Van Reusen, A. K., Shoho, A. R., \& Barker, K. S. (2001). High school teacher attitudes toward inclusion. High School Journal, 84(2), 7-20.

Vaughn, S., Schumm, J.S., Jallad, B., Slusher, J., \& Saumell, L. (1996). Teachers' views of inclusion. Learning Disabilities Research \& Practice, 11(2), 96-106. 
Weddell, K. (2005). Dilemmas in the quest for inclusion. British Journal of Special Education, 32(1), 3-11. https://doi.org/10.1111/j.0952-3383.2005.00363.x

Worrell, F. C. (2008). Nigrescence attitudes in adolescence, emerging adulthood, and adulthood. Journal of Black Psychology, 34(2), 156-178. https://doi.org/10.1177/0095798408315118

Yıldırım, A., \& Şimşek, H. (2008). Qualitative research methods in social sciences (6th edition). Ankara: Seçkin Publishing.

\section{Copyrights}

Copyright for this article is retained by the author(s), with first publication rights granted to the journal.

This is an open-access article distributed under the terms and conditions of the Creative Commons Attribution license which permits unrestricted use, distribution, and reproduction in any medium, provided the original work is properly cited. 